\title{
Strength and microstructural characteristics of palm oil fuel ash and fly ash as binary and ternary blends in Self-Compacting concrete
}

\author{
Brabha Hari Nagaratnam ${ }^{a, *}$, Muhammad Abdul Mannan ${ }^{b}$, Muhammad Ekhlasur Rahman ${ }^{\text {, }}$ \\ Abdul Karim Mirasa ${ }^{\mathrm{d}}$, Alan Richardson ${ }^{\mathrm{a}}$, Omid Nabinejad ${ }^{\mathrm{c}}$ \\ a Department of Mechanical \& Construction Engineering, Northumbria University, Newcastle Upon Tyne NE1 8ST, United Kingdom \\ ${ }^{\mathrm{b}}$ Department of Civil Engineering, Faculty of Engineering, Universiti Malaysia Sarawak, Kota Samarahan, Sarawak 94300, Malaysia \\ 'School of Engineering and Science, Curtin University Sarawak, CDT 25098009 Miri, Sarawak, Malaysia \\ ${ }^{\mathrm{d}}$ School of Engineering E' Information Technology, Universiti Malaysia Sabah, Jln UMS, 88400 Kota Kinabalu Sabah, Malaysia
}

\section{H I G H L I G H T S}

- SCC produced using binary and ternary blend of POFA and FA up to 40\% replacement produced high strength and medium strength concrete. - All binary and ternary blended samples had acceptable splitting tensile strengths and a strong correlation exists between the compressive and tensile strength of the SCC.

- The TGA and SEM analysis of samples with replacement demonstrate lower $\mathrm{Ca}(\mathrm{OH})_{2}$ content than the Control SCC.

- FA SCC exhibit large amount of ettringite at 90 days unlike POFA SCC.

\section{A R T I C L E I N F O}

Article history:

Received 12 June 2018

Received in revised form 17 December 2018

Accepted 21 December 2018

\section{Keywords:}

Binary blend

Ternary blend

Self-compacting concrete

Microstructural properties

Differential thermal analysis

Scanning electron microscopy

\begin{abstract}
A B S T R A C T
This paper evaluates the feasibility of utilising palm oil fuel ash (POFA) and fly ash (FA) as an Ordinary Portland Cement (OPC) replacement in self-compacting concretes (SCC). The level of OPC replacement is up to $40 \%$ based on a $540 \mathrm{~kg} / \mathrm{m}^{3}$ mix design. All concrete mixtures were restricted to the following consistency parameter; slump flow of $750 \pm 100 \mathrm{~mm}, \mathrm{~T}_{500}$ of 1.5-4.0 s, J-Ring diameter of $650 \pm 100 \mathrm{~mm}$, step height of $5-15 \mathrm{~mm}$ and sieve segregation resistance of $<20 \%$. The ternary SCC (TNY) consists of POFA and FA in equal portions. Compressive strength of SCC were determined at 7, 28 and 90 days using both cubes and cylinders. The correlation with the splitting tensile strength were evaluated. Calcium hydroxide (Ca $(\mathrm{OH})_{2}$ ) removal was measured by Differential Thermal Analysis (DTA) and its microstructural properties detected using the Scanning Electron Microscopy (SEM). When comparing the POFA and FA, it was found that the FA outperformed POFA for equal OPC replacements. In addition, the TNY blend had a marked improvement in its microstructural characteristics when compared to POFA and FA. The results also highlight that the addition of POFA and FA at higher replacement levels has significant potential for use as a medium strength concrete. Subsequently, the DTA shows that the $\mathrm{Ca}(\mathrm{OH})_{2}$ for all samples with higher replacement were lower than the control at later ages. It also demonstrated that there was a relationship between $\mathrm{Ca}(\mathrm{OH})_{2}$ with regards to the compressive strength of SCC, which should be useful for forensic investigation that reveals the amount of hydrated products in concrete. Deployment of the two waste by-products of the palm oil and coal ash, would lead to a cleaner and more cost-efficient waste disposal solution for those industries, as well as advantages within the construction sector.
\end{abstract}

Crown Copyright $\odot 2019$ Published by Elsevier Ltd. All rights reserved.

\section{Introduction}

Concrete is an essential material for most construction projects, it consists mainly of cement, aggregate and water. Consequently, cement is the most produced construction material with the current demand, worldwide, amounting to approximately 4 billion tonnes a year [1]. For example, in Malaysia, the rapid development of infrastructure has increased the consumption of cement to 20

\footnotetext{
* Corresponding author.

E-mail addresses: Brabha.nagaratnam@northumbria.ac.uk (B.H. Nagaratnam), mannan@feng.unimas.my (M.A. Mannan), merahman@curtin.edu.my (M.E. Rahman), akmirasa@ums.edu.my (A.K. Mirasa), Alan.richardson@northumbria.ac.uk (A. Richardson), omid.nabinejad@postgrad.curtin.edu.au (O. Nabinejad).
} 